\title{
Innovative Proposals for Incentivizing Drug Development
}

\author{
Kristina M. Lybecker \\ The Colorado College \\ USA
}

\section{Introduction}

The confluence of rising drug costs, more effective innovative medicines, and increasing public outrage have heightened criticism of the pharmaceutical industry and intensified the debate over pharmaceutical prices and access to medicines. As a consequence, policymakers and scholars from a variety of fields have argued for a reexamination of the patent system as an efficient mechanism for encouraging pharmaceutical innovation and drug development. The pharmaceutical industry is uniquely characterized by its production of a social good featuring high fixed costs, substantial informational and regulatory costs, and relatively low marginal costs of production. As such, pharmaceutical innovation is well suited to alternative incentive mechanisms to foster drug development. A variety of alternative mechanisms have been proposed, focusing on welfare improvements ranging from lower drug prices to increased consumer surplus, enhanced access to medicines and greater innovation.

This chapter describes the pharmaceutical industry's existing operating model as well as the subtleties of the current patent system and how it impacts drug development. Second, the chapter explores the characteristics that would make for a socially preferable, welfareenhancing mechanism. Next, the chapter reviews a number of proposed mechanisms and evaluates the advantages and disadvantages of each. The chapter then examines the overwhelming prevalence of "pull" mechanisms, those aimed at incentivizing successful innovation with prizes or other rewards, relative to "push" mechanisms which reduce the cost of research and development through funding awards. Following this, the chapter presents an analysis and comparison of the policy proposals, the similarities in their strengths and limitations, and the characteristics which would enhance the political feasibility of implementation. Finally, the chapter concludes with an appeal for the reexamination of the patent system and further exploration of the promise of alternative mechanisms to enhance access to medicines and incentivize additional research on neglected diseases.

\section{Current environment and challenges to drug development}

The minimum standards for pharmaceutical patent protection are defined by the Agreement on Trade-Related Aspects of Intellectual Property Rights (TRIPS), as set forth by the World Trade Organization (WTO). The TRIPS Agreement was signed in 1995 at the end of the 
Uruguay Round negotiations and requires that all WTO member states provide 20 years of market exclusivity for patented drugs. As a result, the generic products that characterized the pharmaceutical markets of many developing countries prior to TRIPS disappeared as stronger patent protection was adopted. Under TRIPS, generic producers must wait for patent expiry to bring generic versions to market.

The apparatus embodied in the TRIPS Agreement encourage additional pharmaceutical research and development (R\&D) by guaranteeing innovators a period of exclusivity during which they are able to recover their R\&D investments. Without the protection provided by the patent system, innovators would have little incentive to invest in new technologies that could easily be copied and sold by their competitors. Such free riding on the initial investment constitutes a market failure that would stymie most innovation. The market exclusivity incentivizes firms to invest in the difficult and expensive research and development necessary for pharmaceutical advances. This incentive system is the heart of the static/dynamic tradeoff that characterizes the existing patent system. In exchange for temporary (20 years under the existing patent system) monopoly power, a static loss, new knowledge is forever brought into the public domain, a dynamic gain. While the existing patent system has addressed the market failure in one way, there are clearly problems with the current mechanism.

Public health advocates argue that the patent protection afforded by the TRIPS Agreement is a significant determinant in establishing pharmaceutical prices and availability. Specifically, prior to the TRIPS Agreement, developing countries tended to have weaker patent protection (many had no patent protection for pharmaceuticals) which enabled generic drug producers to manufacture generic versions of drugs, even those still under patent protection in industrialized nations. Arguably, this created price competition and lowered drug prices. Critics point to the market exclusivity provided by TRIPS as raising drug prices and reducing availability in the developing world.

Clearly this creates a barrier to access for many of the most vulnerable. In the context of access, "extreme poverty is universally the most important determinant. This is true both for individuals and for countries too poor to fund control efforts fully, still less to undertake needed research." (Musgrove \& Hotez, p.1694)

While poverty and the existing patent system prevent some individuals who would benefit from medical innovations from buying them, a demand side problem, the existing patent system also suffers from problems on the supply side. Glennerster and Kremer (2000) adeptly identify four supply side issues that contribute to the insufficient incentives for innovation: potential purchasers are unwilling (or unable) to pay monopoly prices; some of the benefit from the innovation, in the form of consumer surplus, accrues to consumers; some of the benefit from the innovation is captured by consumers who purchase generic versions after patent expiry; and lastly, some of the benefit goes to other researchers who draw on the original innovation. The authors note that many studies estimate that innovators realize less than half their returns to their inventions. In a similar vein, Kremer (1998) estimates that the social value of a pharmaceutical innovation will be 2.5 times the private value. In essence, for developing countries, the existence of a market is constrained by the poverty of the patients as well as the inability of private researchers to capture the benefits of potential treatments.

The problems embedded in the existing patent system are perhaps more significant in the realm of pharmaceuticals because of the lives that may be lost and the tremendous costs 
associated with untreated diseases. "Some eighteen million human beings die prematurely each year from medical conditions we can cure - this is equivalent to fifty thousand avoidable deaths per day, or one-third of all human deaths." (Pogge, p.182) Musgrove and Hotez (2009) provides an excellent description of the disease burden (death and disability) and economic costs (damage to children's cognitive development and adults' physical productivity) from neglected tropical diseases.

Nevertheless, given the incentives created by the existing patent system, very few resources are devoted to the diseases of the poor. Pharmaceutical research is motivated by potential profits and the diseases endemic to developing nations and the limited purchasing power of these consumers hold little appeal. As described by the World Bank Group (2009), global health research spending is characterized by a 10/90 gap, i.e., less than 10 percent of global health research expenditures are devoted to conditions which account for more than 90 percent of preventable mortality. This imbalance is perhaps best exemplified by the numbers on new drug approvals. Of the "1,556 new drugs approved between 1975 and 2004 , only $21(1.3 \%)$ were specifically developed for tropical diseases and tuberculosis, even though these diseases account for $11.4 \%$ of the global disease burden." (DNDi, p.1) Notably, of these 21 drugs, five emerged from veterinary research. (Poggee, p.190) The absence of a profitable market for neglected tropical disease medicines directs research efforts and resources to other endeavors.

Given the challenges surrounding pharmaceutical pricing, access to medicines, and research on neglected diseases, scholars, public health advocates and policymakers are working to overcome these challenges and design a better mechanism for incentivizing pharmaceutical innovation. In pursuit of a better mechanism, it is important to identify the points in the research and development process where the failures occur. Failures may occur at several stages of the drug development process: insufficient funding for research on neglected diseases, insufficient funding to take potentially promising research forward to the clinical development stage, and distribution problems that prevent existing treatments from reaching patients.

Alternative mechanisms address these failures in one of three ways: those that work within the existing system (compulsory licensing, bulk buying, differential pricing), push mechanisms (research grants, government funding), and pull mechanisms (advance market commitment, prize funds, priority review vouchers). Push mechanisms incentivize pharmaceutical innovation by reducing the cost of research and development. Pull mechanisms remunerate welfare-enhancing innovations with prizes, supplemental profits or other rewards. All mechanisms seek to incentivize pharmaceutical research and development while overcoming particular flaws within the existing system. Greatest emphasis is placed on reducing the price of pharmaceutical innovations and incentivizing work on neglected diseases. Each mechanism is distinguished by its own advantages and limitations, providing a distinct set of benefits and disadvantages to compare to the existing system.

\section{Characteristics of a welfare-enhancing mechanism}

The alternative mechanisms considered below aim to improve upon the existing system, generating additional societal welfare and overcoming some of inefficiencies that plague the current patent regime. Ideally, a new mechanism would improve access to medicines, presumably through lower drug prices, and incentivize additional drug development for 
the treatment of diseases endemic to developing nations. At the same time, a new mechanism would avoid the pitfalls that frequently accompany pharmaceutical innovation. This section describes the welfare-enhancing characteristics that would characterize a preferable mechanism as well as the inefficiencies that should be eliminated. The alternative mechanisms reviewed in the next section are then evaluated in light of the capacity to enhance social welfare and avoid these inefficiencies.

Marginal cost pricing The global patent system and international pharmaceutical market currently engender differential pricing across countries. Through Ramsey Pricing pharmaceutical prices reflect the price elasticity of demand of consumers. The result is higher prices in industrialized nations and lower pharmaceutical prices in the developing world. Access to medicines could be enhanced through more affordable drug prices which would also reduce the deadweight losses associated with monopoly pricing. Most efficient would be marginal cost pricing, prices set equal to the cost of the additional inputs needed to produce one additional unit of output. Marginal cost pricing guarantees that anyone willing to pay the cost of production is able to purchase the good, increasing access and maximizing consumer welfare.

Reduction of pharmaceutical counterfeiting The market exclusivity granted by the existing patent system may result in a substantial mark-up over marginal cost. This mark-up and the associated profitability of the pharmaceutical market create an attractive target for fraudulent production and pharmaceutical counterfeiting. Global health and the security of the international pharmaceutical supply chain would be enhanced if the incentive to counterfeit could be reduced.

Increased RED on treatments for neglected diseases with high social value As repeatedly noted above, the existing system fails to incentivize research on diseases of the poor due to the absence of a profit motive. Overcoming this obstacle to drug development for neglected diseases would enhance global social welfare and provide the potential for therapeutic relief to many of the world's most vulnerable.

Mechanisms for rewarding incremental innovation Although incremental innovations will contribute less to social welfare than innovations that are both first-in-class and best-in-class, it remains important to encourage follow-on innovation. An effective mechanism will reward innovations in proportion to their therapeutic value and will also allow original innovators to capture a share of the returns from all follow-on innovations spurred by the initial advance.

Continued commitments to safety and efficacy Any alternative mechanism should preserve the existing system's commitment to safety and efficacy, ensuring the health of the patient above all. While more rapid review times increase firm profitability, these incentives should not come at the cost of assured safety.

Reduction of excessive marketing Critics frequently point to excessive marketing expenditures within the pharmaceutical industry as a significant contributor to high drug prices. An effective alternative mechanism would incentivize firms to reduce this spending, in essence de-linking profitability and marketing efforts. Elimination of these costs would reduce drug costs and should help to lower prices.

Preservation of the incentives to innovate Alternative mechanisms should preserve the incentives that are in place that encourage innovative activity and foster creativity. Although flawed, the existing patent system effectively does this and has successfully rewarded inventors with returns to their innovations, encouraging a continued stream of innovations and advances. 
Reduced launch times In its current form, the international pharmaceutical market is characterized by differential prices such that drugs are sold at a premium in some countries over others. Given this, firms have an incentive to launch new products in the most profitable nations first, those characterized by higher prices and stronger patent protection. The result may be a significant delay in launch dates for less profitable, frequently developing nation, markets. Reduced launch times, as facilitated by an alternative mechanism, improve global welfare as innovative treatments reach patients more quickly.

Low information costs Alternative mechanisms will ideally require limited, easily attainable information for adoption. Significant informational requirements or difficult (impossible) to obtain information will drive up the cost of implementation.

Reduced duplicative research and development of "me too" drugs The existing patent system and the resultant monopoly prices incentivizes innovators to dedicate R\&D efforts to drugs that are unique enough for a patent award but may provide little or no therapeutic advance. "According to the US Food and Drug Administration, over 77\% of the drugs approved from 1990-2004 were duplicative rather than breakthrough drugs." (Ravvin, p.112 citing a 2005 report by the US Food and Drug Administration) While providing the innovating firm with a return, such duplicative research efforts are an inefficient use of scarce research talent and financial resources. An improved mechanism would provide greater incentives for breakthrough therapies and reduce the incentives for "me too" drugs.

\section{Review of the alternatives to the existing patent system}

As envisioned, the existing patent system seeks to balance the static inefficiency of the temporary monopoly power guaranteed by a patent grant and the dynamic benefits of knowledge spillovers resulting from the sharing of the patented knowledge. While providing incentives to innovate, many argue that the current system has failed the developing world. High drug prices and a dearth of treatments for many neglected and tropical diseases constitute barriers to access to medicines for many patients in the developing world. Frustration with the status quo has driven the call for a reexamination of the patent system and resulted in the development of several alternative mechanisms. The challenges of reforming the patent system and balancing the pharmaceutical industry's incentive to innovate with widespread access to medicines have been approached by numerous scholars in a variety of ways. This section considers nine proposals that have addressed this challenge. Each proposal is described and evaluated in turn. The mechanisms proposed utilize different means to reward pharmaceutical innovation and vary in their ability to enhance access through lower pharmaceutical prices while simultaneously providing a reward to the innovator that would be proportional to the social value of the innovation.

The proposals analyzed here all advocate changes to the existing patent system, through a variety of creative mechanisms advocated from a variety of perspectives. These works date back as far as 1998, and each is characterized by its own set of advantages and challenges, though there is significant overlap in both areas. Each of the proposals is described and examined below.

\subsection{Abramowicz (2003)}

Description: The Abramowicz proposal provides an evaluation of a prize system from the perspective of public administration. This mechanism relies on a retrospective reward 
system to complement the existing patent system. As described, the innovators have the option to elect the prize system, but the decision to participate is irrevocable. Given that the administrative agency has the ability to tailor the procedure for valuing the innovation to the particular patent, the mechanism is flexible which is very attractive. This mechanism provides for the government to reward firms that surrender their patents. The proposal is designed such that the prize is proportional to the patent's value relative to the total value of prize submissions.

Advantages: The Abramowicz mechanism places patents in the public domain, which reduces the static inefficiency associated with monopoly power and the associated deadweight losses. Since the technology is in the public domain, the incentives for "me too" drugs and inventing around existing patents is reduced, removing an additional inefficiency inherent in the existing system. Moreover, projects that would produce high social value that may not be pursued by private firms are incentivized for development through this mechanism.

Limitations: The administrative agency operationalizing this mechanism will require significant amounts of information in order to estimate the value of the innovation. This information will be both difficult and expensive to collect, when it is available. In addition, the innovating firm must also have a great deal of information to accurately determine the quantity of resources to devote to research and development. Specifically, firms require information in order to accurately estimate the social value of every project for which the prize is sought in order to calculate potential returns and the efficient level of investment. Finally, the Abramowicz mechanism is administrated by a government body and is therefore subject to the bureaucratic weaknesses and inefficiencies which characterize government control.

\subsection{Civan (2009)}

Description: Civan proposes extending the patent length beyond 20 years for treatments for diseases which disproportionally affect developing nations. The additional years of patent protection are argued to increase the incentives to research treatments for neglected diseases. Citing the work of Diwan and Rodrik (1991), Civan suggests that patent protection in developing countries could be as much as one and one half times that of patent protection in industrialized countries (20 years under the World Trade Organization).

Advantages: Increased patent length would extend the period of time that pharmaceutical innovators would have to recoup their R\&D investment, enhancing the incentive to research treatments for neglected diseases. This mechanism would be very easy and inexpensive to implement, a law change in participating developing nations would be sufficient.

Limitations: The Civan proposal takes its recommendations from early papers, specifically from static models that may fail to capture important dynamics of the global pharmaceutical market. While enhancing the incentives for research on neglected and tropical diseases, this mechanism would increase the patent length and result in monopoly prices for drugs for a longer period of time in the developing world. Granting that pharmaceutical companies price discriminate, this would still lead to higher prices for the most vulnerable consumers. Given the tremendous opposition to any patent protection for pharmaceuticals in the developing world, one can imagine tremendous opposition to this mechanism by poor nations.

\subsection{Grabowski, Ridley \& Moe (2006, 2009)}

Description: The essence of this policy proposal is the award of a priority review voucher (PRV) to any innovator that gains US FDA (or European Agency for the Evaluation of 
Medicinal Products) approval for a new pharmaceutical or biological treatment for a neglected tropical disease that is shown to be clinically superior to existing treatments. The value of the voucher is that it entitles the bearer to a priority review for another drug submitted for US FDA approval. In contrast to the 15 months required for a standard review, the median review time for a priority review is approximately seven months. The authors find that getting a new drug to market more quickly, even measured in mere months, can be worth hundreds of millions of dollars.

Advantages: The US Congress enacted the Food and Drug Administration Amendments Act of 2007 in September of that year, based on this policy proposal. In September 2009 the PRV program went into effect and the first voucher was awarded to Novartis following the US FDA approval of their anti-malarial drug, Coartem. The priority review voucher is transferable and may either be used or sold by the innovating company. As demonstrated by the experience of the US FDA, the mechanism is straightforward to adopt and operationalize. Regulatory standards for safety and efficacy are preserved, though the priority review does require additional resources at the US FDA to quickly analyze the additional data. The authors claim that the priority review will increase costs to the regulatory agency by approximately $\$ 1$ million per review, though this cost is paid by the innovative firm and amounts to only a small fraction of the value of the voucher. The incentives provided by the priority review voucher are also highly efficient because the innovating firm is able to determine which treatments should be pursued based on internal information and evaluation, increasing the likelihood of success. The incentives provided by the voucher will allow for faster access to blockbuster drugs and increased research on neglected tropical diseases. Based on a study of historical data, Grabowski and Kyle (2007) estimates that the priority review voucher may increase the effective patent life for drugs facing generic entry. In addition, the value of the priority review voucher creates a market mechanism for identifying those drugs for which expedited review is most efficient. Finally, this policy proposal is complementary to other push and pull mechanisms that may be adopted.

Limitations: The proposal requires the US FDA to employ additional resources in order to quickly evaluate the additional regulatory data. The mechanism does not provide for how the treatment will reach patients in developing countries, implementation challenges remain for enhancing access to the medicines. In like manner, while this proposal enhances the incentives for $R \& D$, it fails to address high drug prices as a barrier to access since the mechanism does not specify any conditions on the affordability of the price of the medicinal intervention.

\subsection{Hollis $(2004,2005)$}

Description: The Hollis proposal aims to overcome two of the most significant shortcomings of the existing patent system: the high drug prices which prevent widespread access, and the lack of incentives for research and development on diseases endemic in developing countries. As envisioned, patent rights are relinquished in exchange for a reward calculated to be proportional to the incremental therapeutic benefit of the technology. As an optional reward mechanism, the proposal suggests that this system would operate in conjunction with the current patent system. Key to the Hollis mechanism is the development of an International Pharmaceutical Innovation Fund which would be the source of payments to innovators surrendering their patent rights. Participants would agree to freely license all patents related to the drug when used for developing country markets in exchange for payments for a period of perhaps twelve years. 
Advantages: This mechanism serves as a complement to the existing patent system. The optional reward mechanism would incentivize the development of innovations that provide high social value but are distinguished by low appropriability, precisely the characteristics needed to generate research into neglected diseases. Beyond incentivizing the research, this mechanism also enhances access and reduces deadweight losses by avoiding monopoly pricing. As described, the drugs would be competitively produced and sold at the average cost of production, increasing access for the poor and vulnerable in the developing world. As an additional benefit, the reward is calculated to be proportional to the innovation's social value as determined by a quality-adjusted life year ( $Q A L Y$ ) measure of disease burden, which includes both the quality and the quantity of life lived. In principle, the use of a QALY measure will provide more information than a market-price valuation, and avoid some of the agency and informational problems that currently characterize pharmaceutical markets.

Limitations: In order to operationalize the Hollis proposal, both the administrative agency and the innovating firm must have a great deal of information about the value and cost of the innovation. Determination of the reward requires calculations of both pharmaceutical sales and QALYs for covered innovations, which may be difficult and costly to attain. For the innovator, $R \& D$ investment decisions are based on information about the expected social value of every successful drug in order to calculate the innovator's relative share of the total reward. The mechanisms may induce bureaucratic abuses including regulatory capture and corruption, as well as attempts at gaming the system. Finally, the proposal lacks details on the funding and management of the International Pharmaceutical Innovation Fund.

\subsection{Hubbard \& Love (2004)}

Description: The Hubbard and Love proposal is based on the establishment of a national R\&D contribution with a suggested value of $0.1 \%$ of national Gross Domestic Product (GDP). In line with the existing patent system and current market mechanisms, this contribution could be achieved through the purchase of patent protected drugs (under the assumption that national expenditure on pharmaceuticals is approximately $1 \%$ of GDP and a tenth of the revenue from drug sales is ploughed back into research and development). Alternatively, nations that financed their $R \& D$ contribution in other ways (for example through direct funding of drug development) could place drug patents into the public domain, allowing for competitive production.

Advantages: This mechanism would operate in conjunction with the existing patent system. For those countries electing alternative means of making their $R \& D$ contribution, weaker patent protection would provide for competitive production, lower prices and enhanced access to medicines. In addition, the proposal would eliminate the need for excessive drug marketing and the associated deadweight losses. In principle, funding for pharmaceutical research and development is sustained without the welfare losses generated by monopoly pricing. The authors also claim that $R \& D$ resources will be drawn into the areas of greatest need, though the means by which this will happen is not clear or described.

Limitations: This proposal primarily suffers from informational and measurement challenges. The Hubbard and Love proposal lacks any information on the specifics necessary to operationalize the mechanism: how to calculate and establish the contribution norm, means of global coordination, establishment of an administrative body, distribution of the contribution funds, and design of acceptable alternative mechanisms. Finally, this mechanism requires significant government oversight and control. 


\subsection{Kremer (1998)}

Description: This paper proposes employing a government auction to estimate the private value of patents, then providing an opportunity to buy out the patent at a multiple of this value. In an effort to overcome the insufficient incentives for such research, the multiple would approximate the social value of the innovation. Innovators could opt to sell the patent or retain their rights to the technology. Given a government purchase, patents would be placed in the public domain. In order to avoid distortions and to induce accurate valuations, a fraction of patents would be sold to the highest bidder according to government randomization.

Advantages: The principle advantage of this mechanism is the elimination of monopoly pricing through the placement of patents into the public domain. At the same time, the private incentives to innovate are enhanced to levels closer to the social value since the government aims to establish the buyout at this value. Kremer's proposal provides a market mechanism, specifically auctions, to value innovations and provides for substituting and complementary patents. Patent holders would have the ability to request a second auction in those cases. An additional advantage is the reduced incentive for duplicative research on "me too drugs" through the auction mechanism. Since the patent-generated distortions are severe in the pharmaceutical industry, this mechanism is especially well-suited to this technology. In addition, the U.S. Food and Drug Administration approval process will automatically generate a great deal of the information necessary to value the innovation.

Limitations: A significant criticism of the Kremer mechanism is that transferring the patent into the public domain would reduce the incentive for follow-on research and further development. That is, in the pharmaceutical industry additional clinical development frequently occurs only after a predetermined sales threshold is reached. As such, this proposal may be best suited to the development of vaccines and other specialty products that are narrowly focused with specific, well-defined clinical objectives. In addition, the Kremer mechanism relies upon the assumption that auction participants honestly reveal their valuation of the innovation. Although the government's randomized auction (government purchase of the innovation or sale to the highest bidder) should induce honest valuations, the proposal remains vulnerable to collusion among bidders or bribery from the patent owner.

\subsection{Lanjouw (2002)}

Description: This proposal is predicated on the existence of two types of nations, rich and poor, and two separable drug markets: one for global diseases, such as cancer, and one for diseases endemic to developing nations, such as malaria. In the case of global diseases, Lanjouw's mechanism would require innovating firms to elect to exercise their patent rights in either rich countries or poor countries. This would be done as part of the US Patent and Trademark Office (USPTO) foreign application process, through a declaration attached to the request for a foreign filing license. Nations generating perhaps two percent or less of total global pharmaceutical profit would be defined as poor. For diseases endemic to developing countries, the incentives derived from the patent system would remain in place to encourage innovation. For global diseases with a high incidence in all nations, patent rights exclusive to rich nations would result in competing firms in developing countries where patent protection was not elected, ultimately bringing prices down for developing country residents. As nations developed and markets evolved, the license declaration would be updated to reflect these changes. 
Advantages: The Lanjouw proposal targets patent protection by disease and by country. The mechanism draws on the information advantages possessed by the firm regarding the links between patents, products and diseases, as well as information on the relative size of national markets. The proposal would increase access to medicines in the developing world, for global diseases, while maintaining existing incentives for research on neglected diseases. Finally, the mechanism would be easy and inexpensive to implement, both of which are significant advantages.

Limitations: As envisioned, the Lanjouw proposal requires separation of markets to permit price discrimination. This will be made more difficult by increased globalization, international arbitrage and internet sales. Although the poor nation markets are quite small (two percent), the loss of market power in these countries will (marginally) reduce the incentives to innovate. This mechanism requires information about market size and global pharmaceutical sales that may be difficult to collect. In addition, operationalizing this alternative will require consensus in measurement and in the establishment of the profit share benchmark. Moreover, the policy change describe in this proposal is already available to interested firms on a voluntary basis. One imagines that, however small, the loss of sales revenue from surrendering patent protection is not profitable and therefore the elect not to. Presumably this also indicates that innovative firms would resist the adoption of the changes presented by this mechanism. Finally, the Lanjouw proposal is subject to the lack of stability and consistency in governments' decision-making which may be corrupt, irrational and unpredictable.

\subsection{Lybecker \& Freeman $(2006,2007)$}

Description: The Lybecker \& Freeman proposal rewards innovative firms based on the social value of their drug. The pharmaceutical innovator would receive direct tax credits in exchange for marginal cost pricing, based on production and distribution. The calculation of social value (the sum of consumer and producer surplus) will be based on one year of benchmark sales at market prices, reflecting private value of the innovation. A multiple of this figure will then be utilized to calculate compensation for the patent holder. Participation by innovative firms is voluntary and participation requires marginal cost pricing or licensing the patent for generic production. National participation is also voluntary. Participating nations buy in by providing a share of the financing which is a function of the social value, national disease burden and per capita GDP.

Advantages: While government involvement is inherent in the Lybecker \& Freeman mechanism, the valuation of the innovation continues to be established by market forces. If the innovation offers a therapeutic benefit, a market will emerge in the benchmark year. The efficiency of tax credits is established in earlier work which has shown that one dollar in tax credits for R\&D is associated with one dollar increase in R\&D expenditure at the margin. Duplicative innovations will capture smaller market share and garner smaller direct tax credits. In addition, this mechanism transfers the burden of R\&D financing from those afflicted with a particular disease to all taxpayers, and with global adoption halts the US subsidization of pharmaceutical research and development. Given that firms are expected to freely license the technology, generic competition should emerge to reduce prices to competitive levels in participating nations. Moreover, the mechanism should improve global product dissemination and reduce the launch delays that currently characterize developing country markets. 
Limitations: Implementation will require significant international cooperation on pricing, estimation of social value, financing shares (proportional disease burden and per capital GDP), and reimbursement policies. These calculations will be particularly difficult to make for the least developed countries. In addition, there will be an incentive to manipulate the figures to lower the share of compensation. Since peak sales are reached three to five years post-launch and this proposal uses one benchmark year, this mechanism may underestimate the social value of the innovation. Moreover, given that a single benchmark year is utilized to calculate market valuation, marketing practices may intensify pre-launch and in the benchmark year. Marginal cost pricing is admittedly difficult to estimate and will be a challenging aspect of implementing this proposal. Internet sales and transhipment to nonparticipating nations may make enforcement difficult. Finally, while the Lybecker and Freeman proposal should lower drug prices and increase access to medicines to developing countries, it does not provide additional incentives for research into treatments for neglected diseases.

\subsection{Pogge (2005)}

Description: The Pogge proposal would provide a mechanism to operate in tandem with the existing patent system. Innovative firms would have the option to surrender their conventional patent rights in exchange for an alternative patent which would reward them with a guaranteed payment stream in proportion to the health impact of their medical intervention during its initial 10-12 years of availability. The patent hold would have two options for implementation: grant of an open license to generic producers, or maintaining exclusive production of the drug under the condition that reward payments would be reduced by the amount of sales revenues.

Advantages: Innovative firms would have incentives to develop cost-effective technologies with the maximum health impact. Generic production as well as marginal cost (or less) pricing would be incentivized to maximize access and health improvements among all populations, including the global poor. The mechanism would also discourage duplicative research efforts and excessive marketing. The costs of research and development would be borne globally, by all taxpayers, rather than by those afflicted with a particular disease or condition.

Limitations: Significant challenges are presented by the necessity for measuring an appropriate reward, quantifying the global disease burden and assessing the health impact of new medical interventions, a particularly difficult charge in the context of combination therapies (the so called AIDS "triple cocktail"). In addition, the mechanism requires the coordination of governments and the pharmaceutical industry. The necessary consensus on essential and nonessential drugs may be contentious and subject to political battles and gamesmanship. Moreover, implementation is contingent on raising the resources needed for the Health Impact Fund, an estimated US \$45-\$90 billion annually, a formidable challenge. Pogge problematically asserts that pharmaceutical companies may be willing to bear the additional costs of widespread accessibility, such as improved infrastructure and distribution systems. As argued by Sonderholm (2010), due to the free rider problem, an individual firm has little incentive to invest in the expensive efforts that would then benefit all firms. Finally, there must be agreement on the allocation of the costs across nations, a negotiation process that promises to be difficult and contentious. 
Table 1 below presents a snapshot of the characteristics of each of these proposals, briefly summarizing the authors' perspective, the essence of the proposed mechanism, the proposal's goal, as well as the primary criticisms and advantages of each.

\begin{tabular}{|c|c|c|c|c|c|}
\hline & Perspective & Mechanism & Goal & Criticism & Advantages \\
\hline Abramowicz & Lawyer & $\begin{array}{l}\text { Retrospective } \\
\text { Reward based on } \\
\text { social value }\end{array}$ & $\begin{array}{l}\text { Reduce } \\
\text { DWL, } \\
\text { Access }\end{array}$ & $\begin{array}{l}\text { Government control, } \\
\text { No specifics, } \\
\text { Informational } \\
\text { Requirements } \\
\end{array}$ & $\begin{array}{l}\text { Patents in public } \\
\text { domain, } \\
\text { Complements } \\
\text { patent system }\end{array}$ \\
\hline Civan & Economist & $\begin{array}{l}\text { Longer patent } \\
\text { length in } \\
\text { developing } \\
\text { nations }\end{array}$ & $\begin{array}{l}\text { Therapeutic } \\
\text { Need }\end{array}$ & $\begin{array}{l}\text { Coordination between } \\
\text { nations, Requires lots } \\
\text { of participating } \\
\text { countries, Bad for } \\
\text { global diseases }\end{array}$ & $\begin{array}{l}\text { Market } \\
\text { mechanism, Easy } \\
\text { to implement }\end{array}$ \\
\hline $\begin{array}{l}\text { Grabowski, } \\
\text { Ridley \& } \\
\text { Moe }\end{array}$ & Economists & $\begin{array}{l}\text { Priority Review } \\
\text { Voucher }\end{array}$ & $\begin{array}{l}\text { Therapeutic } \\
\text { Need, Lower } \\
\text { Prices }\end{array}$ & $\begin{array}{l}\text { Smaller prize value } \\
\text { than APC, Potential } \\
\text { for limited clinical } \\
\text { benefits, Safety risks of } \\
\text { Priority Reviewed } \\
\text { Drugs }\end{array}$ & \begin{tabular}{|l|} 
Operationalized \\
and in place \\
Market \\
mechanism at \\
work, Low cost to \\
taxpayers, faster \\
access \\
\end{tabular} \\
\hline Hollis & Economist & $\begin{array}{l}\text { Reward system } \\
\text { via innovation } \\
\text { fund, } \\
\text { QALY } \\
\text { Measurement } \\
\end{array}$ & $\begin{array}{l}\text { Therapeutic } \\
\text { Need, } \\
\text { Access }\end{array}$ & $\begin{array}{l}\text { Government control, } \\
\text { Difficult measurement }\end{array}$ & \begin{tabular}{l|} 
Complements \\
patent system, \\
Reward linked to \\
therapeutic \\
benefit
\end{tabular} \\
\hline $\begin{array}{l}\text { Hubbard \& } \\
\text { Love }\end{array}$ & $\begin{array}{l}\text { Consumer } \\
\text { Advocate }\end{array}$ & $\begin{array}{l}\text { National } \\
\text { contribution } \\
\text { norm via } \\
\text { alternative R\&D } \\
\text { funding models }\end{array}$ & $\begin{array}{l}\text { Therapeutic } \\
\text { Need, Lower } \\
\text { Prices }\end{array}$ & $\begin{array}{l}\text { No Specifics, } \\
\text { Government Control }\end{array}$ & $\begin{array}{l}\text { Continued R\&D } \\
\text { fund via } \\
\text { mandated } \\
\text { contribution }\end{array}$ \\
\hline Kremer & Economist & $\begin{array}{l}\text { Patent Buyout via } \\
\text { Auction } \\
\text { mechanism }\end{array}$ & $\begin{array}{l}\text { Reduce } \\
\text { DWL, } \\
\text { Pay Social } \\
\text { Value } \\
\end{array}$ & $\begin{array}{l}\text { Collusion, } \\
\text { Further development } \\
\text { discouraged }\end{array}$ & $\begin{array}{l}\text { Market } \\
\text { Mechanism } \\
\text { Public domain } \\
\text { patents } \\
\end{array}$ \\
\hline Lanjouw & Economist & $\begin{array}{l}\text { Patents tailored } \\
\text { to two different } \\
\text { drug markets }\end{array}$ & $\begin{array}{l}\text { Therapeutic } \\
\text { Need, } \\
\text { Access }\end{array}$ & $\begin{array}{l}\text { Enforcing separate } \\
\text { markets, Industry } \\
\text { cooperation }\end{array}$ & $\begin{array}{l}\text { Low cost, Easy to } \\
\text { Implement }\end{array}$ \\
\hline $\begin{array}{l}\text { Lybecker \& } \\
\text { Freeman }\end{array}$ & Economists & $\begin{array}{l}\text { Direct Tax } \\
\text { Credits to fund } \\
\text { innovation }\end{array}$ & $\begin{array}{l}\text { Therapeutic } \\
\text { Need, } \\
\text { Access, } \\
\text { Lower Prices }\end{array}$ & $\begin{array}{l}\text { Difficult } \\
\text { measurement, } \\
\text { consensus, } \\
\text { global cooperation }\end{array}$ & $\begin{array}{l}\text { Marginal Cost } \\
\text { pricing, faster } \\
\text { launch times, } \\
\text { reduced } \\
\text { duplicative } \\
\text { research } \\
\end{array}$ \\
\hline Pogge & $\begin{array}{l}\text { Political } \\
\text { Scientist }\end{array}$ & $\begin{array}{l}\text { Reward system } \\
\text { based on health } \\
\text { impact }\end{array}$ & $\begin{array}{l}\text { Therapeutic } \\
\text { Need, } \\
\text { Lower Prices }\end{array}$ & $\begin{array}{l}\text { Publicly funded, } \\
\text { challenging } \\
\text { measurement, global } \\
\text { cooperation necessary }\end{array}$ & $\begin{array}{l}\text { Incentive to } \\
\text { maximize health } \\
\text { benefit, incentives } \\
\text { for cost-effective } \\
\text { drugs }\end{array}$ \\
\hline
\end{tabular}

Table 1. Summary of Proposals 
The selection of proposals examined here represents a variety of perspectives, from economist to lawyer to political scientist, and utilize a variety of mechanisms to incentivize drug development, from auction to tax policy to license declaration. The objectives of most of the proposals focus on improved access to medicines for the poor, especially patients in developing nations, enhanced research on neglected diseases and reduced deadweight loss. Unfortunately there is also great commonality in the limitations of the mechanisms: large (sometimes impossible) informational requirements, tremendous government involvement, dearth of details, and coordination challenges.

\section{Comparison and analysis}

This section seeks to compare and contrast the nine proposals presented above. Specifically, given the alternative policy proposals considered here, the following questions must be answered: How do they differ and how are they most similar? Which are the most politically feasible? What are the greatest advantages? What are the most significant limitations?

As described earlier, alternatives to the existing patent system fall into three categories: those that work within the existing system, push mechanisms and pull mechanisms. Push mechanisms reduce the cost of research and development while pull mechanisms reward successful innovation with prizes, supplemental profits, or some other reward. In essence, push mechanisms reward effort while pull mechanisms reward results. Of the policy proposals considered here, eight of the nine would be described as pull mechanisms. The sole push mechanism is the one advocated by Hubbard and Love (2004) which proposes a national R\&D contribution nom to be met by any means, which could then expand direct funding for drug development.

The remaining eight proposals are all forms of pull mechanisms ranging from priority review vouchers to longer patent lives in developing nations, to direct tax credits. Given that so many of these proposals focus on pull mechanisms, one must ask whether this is a superior approach to the challenges surrounding neglected diseases and barriers to access. In an excellent discussion of the comparative advantages of push vs. pull mechanisms Grace and Kyle (2009) examine the strengths and weaknesses of each. In the context of pull mechanisms, there are several important advantages. Grace and Kyle note that economic principal-agent models suggest that pull mechanisms are superior when agents are not capital constrained, when it is straightforward to specify the desired innovation and its specific characteristics, and when the principal is risk-averse. Perhaps most advantageous is the fact that pull mechanisms only reward successful outcomes. This correctly aligns the firms' incentives: only those whose chances of success are great enough will be willing to invest the resources necessary for research and development. The market mechanisms work to ensure those best able to succeed are those most likely to participate. Pull mechanisms allow for the contributions of a large, varied and disperse group of experts and researchers. While this may increase the speed of innovation, it may also risk duplicative research efforts. On the other hand, Grace and Kyle argue that push mechanisms may be considered superior when effort is easy to monitor and measure and when the principal has a greater tolerance for risk. An important advantage of push funding is the elimination of research and development risk since the funding is assured regardless of results. This is particularly beneficial for encouraging basic research, though it is arguably inefficient since many funded research efforts are unsuccessful and de-linking risk and reward may incentivize less fruitful efforts. 
The pull characteristic is not the only similarity across the proposals considered in this chapter. Importantly, the majority of mechanisms are focused on incentivizing research on those diseases for which there is greatest therapeutic need and enhancing access to medicines through lower drug prices. Though the means to the end are very different across the proposals, the goals are virtually identical.

The proposals are also characterized by similar advantages and limitations. Perhaps the most common advantage seen across the alternative mechanisms is the reliance on a market mechanism to incentivize invention and determine the valuation of the innovation. This both ensures that resources are invested prudently (risks are balanced against potential returns) and that research efforts are pursued by the most efficient firms. In the case of the limitations, those most frequently cited are informational requirements and coordination/cooperation challenges. The uncertainty surrounding both of these elements poses a noteworthy challenge to implementation in each case.

Finally, it is important to consider which of the nine policy proposals are the most politically feasible. In this spirit, it is valuable to reflect on the Priority Review Voucher (Grabowski, Ridley and Moe) which went into effect in the United States in September of 2009. Several aspects of this mechanism are politically attractive and important to the likelihood of adoption. First, this mechanism is optional for the firm. This ensures greater buy-in by the industry, which will be favourably received by policymakers as well. It is also voluntary at the national level. While the United States is now experimenting with the Priority Review Voucher, other nations have the option of instituting a similar mechanism to enhance their patent systems as well. In addition, mechanisms that complement the existing system will be easier and less costly to adopt than those that require a new institutional architecture for adoption. Again, such mechanisms would be implementable at the discretion of national authorities. Lastly, the most politically feasible mechanisms will utilize the market forces which preserve the incentives to innovate through potential profits. Market forces are highly efficient and ensure that resources are invested only when risk levels and expected returns warrant that investment.

Overall it is apparent that the majority of creative thinking in the realm of alternatives patent mechanisms utilize pull mechanisms to both incentivize research on neglected diseases as well as lower drug prices to enhance access to medicines. While the policy proposals vary greatly in the design of their mechanisms, there are tremendous similarities in their strengths and limitations. Ultimately the value of these proposals will lie in the change they engender: through their implementation and/or the creative thinking they inspire. While only one of these proposals has been operationalized, it is clear that there is a set of identifiable characteristics making adoption more politically feasible and therefore likely.

\section{Conclusions}

The current policy debate over pharmaceutical patents and drug development is largely focused on the high prices which create a barrier to access for many consumers in the developing world. An obvious tension exists between public health policy and shareholder expectations. Emotionally charged discussions frequently ignore the importance of research and development funding to a productive pipeline of therapeutic compounds and new pharmaceutical compounds. The growing public outrage has inspired scholars and policymakers to re-examine the patent system and search for alterative mechanisms capable 
of incentivizing pharmaceutical innovation which simultaneously ensuring greater access to medicines.

This chapter presents a review of nine alternative policy proposals seeking to reward innovation while improving social welfare. As an industry which produces social goods characterized by high fixed and/or sunk costs and relatively low marginal costs of production, the pharmaceutical industry is well-suited to an alternative mechanism which may greatly improve global social welfare. The challenges of improving access to medicines and incentivizing research on neglected diseases demand creative thinking to overcome the tremendous loss of life and quality of life. Although the advantages to these proposals are significant, each is also characterized by costs and drawbacks that limit the potential for implementation. In spite of this, growing frustration with the existing system and increasing criticism of the pharmaceutical industry point to the need for consideration of alternatives and indicate these policy proposals are worth exploring.

\section{References}

Abramowicz, Michael. "Perfecting Patent Prizes," Vanderbilt Law Review, vol.56, no.1, January 2003, pp.114-236.

Civan, Abdülkadir. "An Alternative Patent Mechanism for Pharmaceutical Drugs for Tropical Diseases," European Journal of Economic E Political Studies, vol.2, no.1, 2009.

Diwan, I. and D. Rodrik. "Patents, appropriate technology and North-South trade," Journal of International Economics, February 1991, vol.30, no.1-2, pp.27-47.

Drugs for Neglected Diseases Initiative (DNDi). "Landscape for R\&D," online posting. Available from: http://www.dndi.org/business-model/landscape.html (last accessed 1 July 2011)

Glennerster, Rachel and Michael Kremer. "A Better Way to Spur Medical Research and Development," Regulation, 2000, vol.23, no.2, pp.34-39.

Grabowski, Henry G. and Margaret Kyle. "Generic Competition and Market Exclusivity Periods in Pharmaceuticals," Managerial and Decision Economics, 2007, vol.28, pp.491-502.

Grabowski, Henry G., David B. Ridley, and Jeffrey Moe. "Encouraging Innovative Treatment of Neglected Disease through Priority Review Vouchers," in Karen Eggleston (eds.) Prescribing Cultures and Pharmaceutical Policy, Stanford University, The Walter H. Shorenstein Asia-Pacific Research Center, 2009, pp.347365 .

Grace, Cheri and Margaret K. Kyle. “Comparative advantages of push and pull incentives for technology development: lessons for neglected disease technology development" Global Forum Update on Research for Health, vol.6, 2009, pp.147151. Available online from: http://www.globalforumhealth.org/MediaPublications/Publications/Global-Forum-Update-on-Research-for-Health-Volume6-Innovating-for-the-Health-of-All (last accessed 4 July 2011)

Hollis, Aidan. "Optional Rewards for New Drugs for Developing Countries," working paper, Department of Economics, University of Calgary, April 2005. Available from http://econ.ucalgary.ca/fac-files/ah/optionalrewards.pdf

Hollis, Aidan. "An Efficient Reward System for Pharmaceutical Innovation," working paper, Department of Economics, University of Calgary, June 2004. Available from http:/ / econ.ucalgary.ca/fac-files/ah/drugprizes.pdf 
Hubbard, Tim and James Love. "A New Trade Framework for Global Healthcare R\&D," PLoS Biology, February 2004, vol.2, issue 2, pp.0147-0150.

Kremer, Michael. "Patent Buyouts: A Mechanism for Encouraging Innovation," Quarterly Journal of Economics, vol.113, no.4, November 1998, pp.1137-67.

Lanjouw, J.O. A patent policy for global diseases: US and international legal issues. Harvard Journal of Law and Technology, vol.16, no.1, 2002, pp.85-124.

Lybecker, Kristina M. and Robert A. Freeman. "Funding Pharmaceutical Innovation through Direct Tax Credits," Journal of Health Economics Policy \& Law, August 2007, volume 2, issue 03, pp 267-284.

Lybecker, Kristina M. and Robert A. Freeman. “Drugs \& Taxes: Lower Prescription Drug Prices through Direct Tax Credits," Journal of Pharmaceutical Finance, Economics \& Policy, 2006, volume 14, no.2, pp.69-95.

Musgrove, Philip and Peter J. Hotez. "Turning Neglected Tropical Diseases into Forgotten Maladies," Health Affairs, vol.28, no.6, November/December 2009, pp.1691-1706.

Pogge, Thomas W. "Human Rights and Global Health: A Research Program," in Christian Barry and Thomas Pogge, eds. Global Institutions and Responsibilities: Achieving Global Justice, Oxford: Blackwell, 2005, pp.190-217.

Ravvin, Michael. "Incentivizing Access and Innovation for Essential Medicines: A Survey of the Problem and Proposed Solutions," Public Health Economics, vol.1, no.2, 2008, pp.110-123.

Ridley, David B., Henry G. Grabowski and Jeffrey L. Moe. “Developing Drugs for Developing Countries," Health Affairs, vol.25, no.2, 2006, pp.313-324.

Sonderholm, Jorn. "A Reform Proposal in Need of Reform: A Critique of Thomas Pogge's Proposal for How to Incentivize Research and Development of Essential Drugs," Public Health Ethics, vol.3, no.2, 2010, pp.167-177.

World Bank Group. "The Global Forum for Health Research," Independent Evaluation Group, Washington, DC, 23 June 2009. Available from: http:/ / siteresources.worldbank.org/EXTGLOREGPARPROG/Resources/gfhr.pdf (last accessed 1 July 2011) 


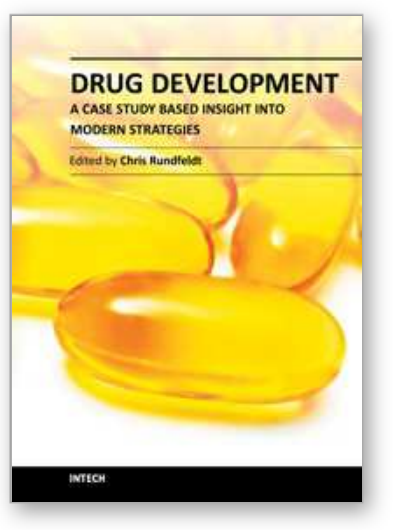

\author{
Drug Development - A Case Study Based Insight into Modern \\ Strategies \\ Edited by Dr. Chris Rundfeldt
}

ISBN 978-953-307-257-9

Hard cover, 654 pages

Publisher InTech

Published online 07, December, 2011

Published in print edition December, 2011

This book represents a case study based overview of many different aspects of drug development, ranging from target identification and characterization to chemical optimization for efficacy and safety, as well as bioproduction of natural products utilizing for example lichen. In the last section, special aspects of the formal drug development process are discussed. Since drug development is a highly complex multidisciplinary process, case studies are an excellent tool to obtain insight in this field. While each chapter gives specific insight and may be read as an independent source of information, the whole book represents a unique collection of different facets giving insight in the complexity of drug development.

\title{
How to reference
}

In order to correctly reference this scholarly work, feel free to copy and paste the following:

Kristina M. Lybecker (2011). Innovative Proposals for Incentivizing Drug Development, Drug Development - A Case Study Based Insight into Modern Strategies, Dr. Chris Rundfeldt (Ed.), ISBN: 978-953-307-257-9, InTech, Available from: http://www.intechopen.com/books/drug-development-a-case-study-based-insight-intomodern-strategies/innovative-proposals-for-incentivizing-drug-development

\section{INTECH}

open science | open minds

\section{InTech Europe}

University Campus STeP Ri Slavka Krautzeka 83/A 51000 Rijeka, Croatia Phone: +385 (51) 770447

Fax: +385 (51) 686166 www.intechopen.com

\section{InTech China}

Unit 405, Office Block, Hotel Equatorial Shanghai No.65, Yan An Road (West), Shanghai, 200040, China 中国上海市延安西路65号上海国际贵都大饭店办公楼405单元 Phone: +86-21-62489820

Fax: +86-21-62489821 
(C) 2011 The Author(s). Licensee IntechOpen. This is an open access article distributed under the terms of the Creative Commons Attribution 3.0 License, which permits unrestricted use, distribution, and reproduction in any medium, provided the original work is properly cited. 